\title{
Comparative Trial of Pancrex V Forte and Nutrizym in Treatment of Malabsorption in Cystic Fibrosis
}

\author{
MARY C. GOODCHILD, E. SAGARÓ, G. A. BROWN, PATRICIA M. CRUCHLEY, \\ HILDA R. JUKES, CHARLOTTE M. ANDERSON
}

\begin{abstract}
Summary
A cross-over trial of pancreatic enzyme replacement therapy has been conducted on 12 children with cystic fibrosis using Pancrex $V$ forte and Nutrizym tablets in equivalent dosage. No differences were found in the effectiveness of these products as measured by stool volume, number of bowel actions, faecal fat excretion, and urine urea excretion. Neither product eliminated the steatorrhoea. Though there was no laboratory evidence to support their choice nine patients expressed a preference for Nutrizym at the conclusion of the trial. This preference was based partly on the smaller number of tablets which are required.
\end{abstract}

\section{Introduction}

Pancreatic enzyme insufficiency is common in cystic fibrosis and is predominantly responsible for the maldigestion of fat and protein. Preparations of animal pancreas given by mouth reduce stool fat and nitrogen losses but normal faecal levels are rarely achieved (Harris et al., 1955; Ross, 1955; Matthews and Spector, 1961; Lapey et al., 1974).

Consequently we were interested to examine the effects in children of a different preparation, Nutrizym, which in comparison with Pancrex $\mathrm{V}$ forte was reported by Knill-Jones et al. (1970), in a study on 12 young adults, 11 of whom had cystic fibrosis, to be significantly more effective in improving fat absorption. Some reduction of faecal weight and improvement in protein digestion with Nutrizym were also recorded by these authors.

\section{Composition and Action of Tablets}

Nutrizym tablets are of composite structure with an external sugar coating which dissolves in gastric contents at a pH of between 3 and 8 to uncover a shell of bromelain, a proteolytic enzyme derived from pineapple. Unlike trypsin this enzyme is said to be active both in the stomach and in the small gut. The next layer, an enteric coat, disintegrates at a $\mathrm{pH}$ of 6.0 to 8.5 to release a central core of pancreatin powder and $30 \mathrm{mg}$ of an ox bile preparation, of which $45 \%$ is cholic acid.

Pancrex V forte tablets are enteric coated, the coating being designed to disintegrate at a $\mathrm{pH}$ of 6 or over to release Pancrex V powder.

In-vitro analysis of the two tablets performed in the same laboratory by the new B.P. method showed that Pancrex V forte tablets contained protease 260 units, lipase 4,876 units, and amylase 3,244 units per

\footnotetext{
Institute of Child Health, University of Birmingham, Birmingham B16 8ET

MARY C. GOODCHILD, M.B., D.C.H., Research Fellow (Clinical)

E. SAGARO, M.D., W.H.O. Training Fellow in Gastroenterology

E. SAGARO, M.D., W.H.O. Training Fellow in Gast

G. A. BROWN, B.SC., Senior Research Associate

PATRICIA M. CRUCHLEY, Medical Student

HILDA R. JUKES, S.R.N., Dietician

CHARLOTTE M. ANDERSON, M.SC., F.R.C.P., Professor of Paediatrics and Child Health and Director of Institute
}

tablet and that Nutrizym tablets contained protease 636 units, lipase 10,280 units, and amylase 13,635 units per tablet. Thus with the exclusion of the amylase values two tablets of Pancrex $V$ forte were regarded as having enzyme activity equivalent to one tablet of Nutri$\mathrm{zym}$, and that dosage ratio was used in the trial.

\section{Patients and Methods}

Twelve patients (seven boys and five girls aged 5 to 15 years) took part in a cross-over trial conducted on an outpatient basis. In all cases cystic fibrosis was diagnosed by the finding of abnormally high sweat sodium and chloride levels, increased faecal fat excretion, and other characteristic clinical features. A family history was present in five cases and in a sixth the child had presented at birth with meconium ileus.

Pancrex V forte tablets were given with meals for two weeks (mean number taken per week 184, range 67-387) followed by Nutrizym tablets for two weeks (mean number taken per week 92, range 35-214). The dosage of Pancrex $V$ forte tablets had been established by the parents before the trial as being the most effective one for reducing stool frequency and size. On account of the relative enzyme contents of the tablets, the Nutrizym tablet having the greater enzyme content (see above), a dosage ratio of two tablets of Pancrex $\mathrm{V}$ forte to one tablet of Nutrizym was used throughout the trial.

Fat intake was that provided by the usual home diet and parents recorded the type and quantity of all food taken during each week of the four-week period. Medicines were also recorded. In addition parents and children kept an account of the daily number of bowel actions, describing stool odour and consistency; abdominal pain, "wind," and incidental illnesses were also noted. An assessment of product palatability was made at the completion of the trial, and participants were asked if they had a preference for either product and if so to give reasons for this preference.

Three-day stool collections and 24-hour urine collections (containing $1 \mathrm{ml}$ of sodium azide $20 \mathrm{~g} / 100 \mathrm{ml}$ ) were made at the end of each week of the four-week trial. An assessment of the effectiveness of the tablets was made by comparison of stool volume, number of bowel actions, faecal fat excretion, and urine urea excretion during the two-week periods on each preparation. The choice of urine urea was based on the report of Coltini et al. (1973), who, in a study of nitrogen balance in adults without known malabsorption problems, described a positive correlation between urine urea and nitrogen absorption which was independent of the state of nitrogen balance. Thus an improvement of nitrogen absorption with the use of either of the preparations should have been reflected in an increase in the excretion of urea.

\section{LABORATORY MEASUREMENTS}

Faecal fat analysis was performed by the method of Van de Kamer et al. (1949) as modified by Anderson et al. (1952). Urine urea was estimated by the method of Fawcett and Scott (1960) and urine creatinine by the method of Bonsnes and Taussky (1945). Urea excretion was expressed in $\mathrm{g} / 24$ hours, and because of the problems inherent in the collection of accurately timed urine specimens from children it was also expressed as $\mathbf{g}$ of urea/mg of creatinine/24 hours. 


\section{Results}

\section{CLINICAL AND LABORATORY ASSESSMENT OF PRODUCTS}

The mean faecal fat excretion and urine urea excretion during treatment with each of the two products are shown in the chart. When the results for stool volume, number of bowel actions, and faecal fat and urine excretion were compared by Student's paired $t$ test (table $\mathrm{I})$ no significant difference $(P<0.05)$ was found. Urine urea excretion expressed as $\mathrm{g}$ of $\mathrm{urea} / \mathrm{mg}$ of creatinine/ 24 hours also failed to show a significant difference.
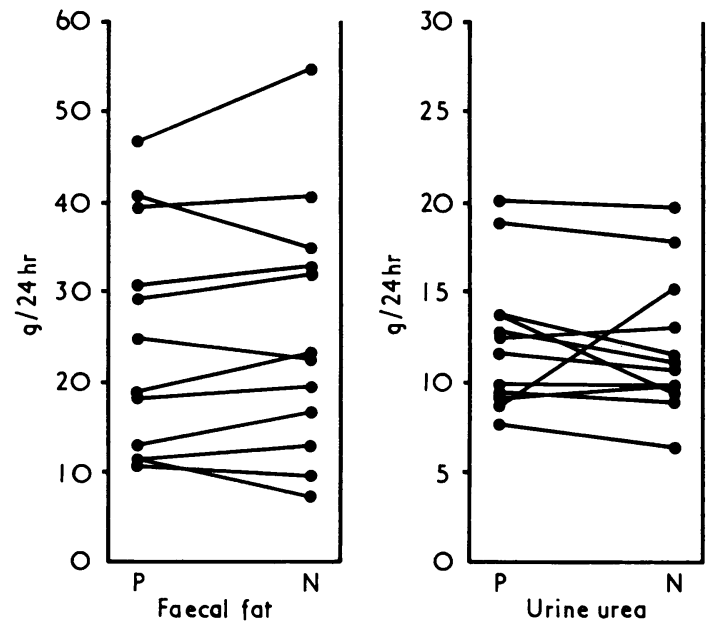

Faecal fat and urine urea excretion. Comparison of mean values obtained during two weeks on Pancrex $V$ forte $(P)$ and two weeks on Nutrizym (N). Lines connect values from individual patients.

TABLE I-Comparison by Student's Paired t Test of Stool Volume, Number of Bowel Actions, Faecal Fat, and Urine Urea Excretion (Mean Values for Two Weeks on Pancrex V Forte Compared With Mean Values for Two Weeks on Nutrizym)

\begin{tabular}{|c|c|c|c|c|c|}
\hline & & & & $\begin{array}{c}\text { No. of } \\
\text { Patients }\end{array}$ & $\mathbf{P}$ \\
\hline $\begin{array}{l}\text { Stool volume ( } \mathrm{ml} / 3 \text { days) } \\
\text { No. of bowel actions a week } \\
\text { Faecal fat ( } \mathrm{g} / 3 \text { days) }\end{array}$ & $\begin{array}{l}\cdots \\
\cdots\end{array}$ & $\begin{array}{l}\cdots \\
\therefore\end{array}$ & $\begin{array}{l}\cdots \\
\cdots\end{array}$ & $\begin{array}{r}12 \\
9 \\
12\end{array}$ & $\begin{array}{l}0 \cdot 2-0 \cdot 1 \\
0 \cdot 3-0 \cdot 4 \\
0 \cdot 3-0 \cdot 4\end{array}$ \\
\hline Urine urea $(\mathrm{g} / 24 \mathrm{hr})$ & .. & .. & . & 12 & $0.6-0.7$ \\
\hline
\end{tabular}

TABLE II-Calculations Based on Mean Values for the 12 Patients as a Group

\begin{tabular}{|c|c|c|}
\hline & $\begin{array}{c}\text { Pancrex V } \\
\text { Forte }\end{array}$ & Nutrizym \\
\hline $\begin{array}{l}\text { Mean No. of tablets taken per week } \pm \text { S.D. . . } \\
\text { Mean stool volume (ml/3 days) } \pm \text { S.D. } \\
\text { Mean No. of bowel actions per week } \pm 1 \text { S.D. } \\
\text { Mean faecal fat excretion }(\mathrm{g} / 24 \mathrm{hr}) \pm \pm \text { S.D. .. }\end{array}$ & $\begin{array}{rr}184 & \pm 118 \\
779 & \pm 278 \\
11 \cdot 7 & \pm 4 \cdot 5 \\
24 \cdot 3 & \pm 12 \cdot 5\end{array}$ & $\begin{array}{l}92+61 \\
884 \pm 505 \\
10 \cdot 8 \pm 5 \cdot 1 \\
25 \cdot 3 \pm 13.7\end{array}$ \\
\hline
\end{tabular}

The results for the 12 subjects are combined in table II. About half the number of Nutrizym tablets were taken compared with Pancrex $\mathrm{V}$ forte, to conform to the different enzyme contents of the tablets, and the mean figures for stool volume, number of bowel actions, and faecal fat excretion were similar with the two preparations.

\section{PARENT'S RECORDS}

Information on the fat intake recorded each day by the parents and discussions between the parents and the dietician (H.R.J.) allowed calculation of the children's fat intake while they were on Pancrex V forte and Nutrizym. Mean values over 24 hours were calculated on a two-day and a three-day basis for each child for each week and the close similarity between the figures suggested that the two-day mean value was adequate to compare the fat intake on each enzyme preparation (for the group as a whole two- and three-day mean fat intakes on Pancrex $V$ forte were 65.5 and $65.2 \mathrm{~g} / 24$ hours respectively and two- and threeday mean fat intakes on Nutrizym were 64.7 and $64.9 \mathrm{~g} / 24$ hours respectively). Figures for fat intake, faecal fat, and coefficients of fat absorption are shown in table III. In two children (cases 2 and 5) the coefficient of fat absorption was nil, and in the others the figures ranged from $52 \cdot 4 \%$ (case 3 ) to $90 \cdot 3 \%$ (case 9 ). With the exclusion of cases 2 and 5 the mean coefficients of absorption on Pancrex V forte and Nutrizym were $70 \cdot 1 \%$ and $69 \cdot 2 \%$ respectively.

The record sheets also showed that medicines were not altered during the trial. The change from Nutrizym to Pancrex $\mathrm{V}$ forte resulted in no striking differences in stool character or in the occurrence of abdominal pain or "wind." Incidental illnesses were few and were judged to have played little part in the food intake and bowel pattern.

\section{FINAL QUESTIONNAIRE}

This questionnaire was completed by the parents at the end of the trial. Of the 12 patients nine preferred Nutrizym, one preferred Pancrex V forte, and two thought that the products were of equal effect.

Of the nine patients who preferred Nutrizym three did so solely because they considered that the product was easier and more pleasant to take (a reflection in part of the reduced number of tablets); three others agreed with this and thought in addition that stools were less frequent and more formed and that abdominal pain and "wind" were decreased; two commented on an improved stool character and less abdominal pain, and one gave more formed stools as the reason for his choice. The patient who preferred Pancrex $\mathrm{V}$ forte did so on account of more formed and less frequent stools.

\section{Discussion}

We have been unable to confirm the results of Knill-Jones et al. (1970), who reported a decrease in faecal fat excretion of 14.8

TABLE III-Fat Intake, Faecal Fat, and Coefficient of Fat Absorption while Patients were on Pancrex V Forte and Nutrizym

\begin{tabular}{|c|c|c|c|c|c|c|c|}
\hline \multirow{2}{*}{ Case No. } & \multirow{2}{*}{ Age (Years) } & \multicolumn{2}{|c|}{ Mean 24-hr Fat Intake (g) on: } & \multicolumn{2}{|c|}{ Mean 24-hr Faecal Fat (g) on: } & \multicolumn{2}{|c|}{$\%$ Coefficient of Fat Absorption on: } \\
\hline & & Pancrex & Nutrizym & Pancrex & Nutrizym & Pancrex & Nutrizym \\
\hline $\begin{array}{r}1 \\
2 \\
3 \\
4 \\
5 \\
6 \\
7 \\
8 \\
9 \\
10 \\
11 \\
12\end{array}$ & $\begin{array}{r}5.7 \\
6.6 \\
7.0 \\
8.7 \\
8.7 \\
8.8 \\
9 \cdot 0 \\
9 \cdot 2 \\
9 \cdot 7 \\
10.0 \\
14.2 \\
15.0\end{array}$ & $\begin{array}{r}44 \cdot 8 \\
39.2 \\
84 \cdot 5 \\
71.3 \\
38 \cdot 2 \\
83.9 \\
76 \cdot 2 \\
79 \cdot 2 \\
109 \cdot 6 \\
43.9 \\
78 \cdot 7 \\
36 \cdot 2\end{array}$ & $\begin{array}{c}40 \cdot 1 \\
39 \cdot 3 \\
85 \cdot 6 \\
74.9 \\
39 \cdot 8 \\
88.1 \\
60.9 \\
86.8 \\
96.1 \\
39 \cdot 1 \\
86 \cdot 8 \\
39 \cdot 2\end{array}$ & $\begin{array}{l}11.4 \\
45.8 \\
40.2 \\
28.6 \\
39.0 \\
18.8 \\
24.8 \\
18.4 \\
10.6 \\
11.3 \\
30.0 \\
12.6\end{array}$ & $\begin{array}{r}12.8 \\
53.8 \\
34.3 \\
31.6 \\
40.0 \\
23.5 \\
22.6 \\
19.3 \\
9.5 \\
7.2 \\
32.5 \\
16.6\end{array}$ & $\begin{array}{c}74 \cdot 6 \\
0.0 \\
52.4 \\
59.9 \\
0 \\
77.6 \\
67.5 \\
76.8 \\
90.3 \\
74.3 \\
61.9 \\
65.2\end{array}$ & $\begin{array}{c}68.0 \\
0.9 \\
59.9 \\
57.8 \\
0 \\
73.3 \\
62.9 \\
77.8 \\
90.1 \\
81.6 \\
62.6 \\
57.7\end{array}$ \\
\hline
\end{tabular}


g/day when their patients were on Nutrizym (mean fat excretion $42.5 \mathrm{~g}$ ) compared with when they were on Pancrex $\mathrm{V}$ forte (mean fat excretion $57.3 \mathrm{~g}$ ). Our patients' fat excretion was closely similar with both products $(25.3 \mathrm{~g}$ on Nutrizym and $24.3 \mathrm{~g}$ on Pancrex V forte). Before the start of our trial patients had been taking Pancrex $\mathrm{V}$ forte in a dosage which had been established by the parents as being the most effective one for reducing stool frequency and improving stool character. All patients continued with this regimen for the first two weeks of the trial so that dosage and relevant details could be recorded, and the number of tablets was halved (though the enzyme dose for trypsin and lipase remained the same) during the two weeks when Nutrizym was given. Knill-Jones et al. (1970) chose to use suboptimal doses of pancreatic replacement therapy to facilitate the detection of improved digestion with either of the two preparations. Our doses resulted in smaller faecal fat excretions, but these were still sufficiently abnormal, we believe, for any differences in the effectiveness of the tablets to be apparent.

In addition we did not find a significant difference in stool volume (mean volume $294 \mathrm{ml} /$ day on Nutrizym and $259 \mathrm{ml} /$ day on Pancrex V forte). Knill-Jones et al. (1970), who recorded stool weights (444 g/day on Nutrizym and $514 \mathrm{~g}$ /day on Pancrex $\mathrm{V}$ forte), pointed out that the reduction in stool weight was not significant.

A consideration of the dosage regimen chosen by Knill-Jones et $a l$. in their trial may explain the differences between their findings and ours. The analysis of the enzyme content of the tablets used in their trial (trypsin and lipase 2,500 and 8,100 units respectively for Nutrizym, and 1,230 and 4,000 units respectively for Pancrex $\mathrm{V}$ forte) suggests that a dosage ratio of two tablets of Pancrex $\mathrm{V}$ forte to one tablet of Nutrizym would have been approximately equivalent. The ratio of three tablets of Pancrex V forte to two tablets of Nutrizym used by Knill-Jones et al., however, represented a reduction in Pancrex $\mathrm{V}$ forte dosage of $25 \%$. The relative increase of the Nutrizym dose may have been sufficient to account for the reported decreases in stool fat and stool weight.

Our method of evaluating protein digestion by a measurement of urine urea excretion did not show an enhancement of nitrogen absorption with either product. Protein digestion as assessed by Knill-Jones et al. by the measurement of urine hydroxyproline excretion after a gelatin meal was not practicable for use in our children on an outpatient basis. Thus we are unable to comment on their observation that "the proteolytic action of Nutrizym started earlier and finished before that of Pancrex," though we note the observation that "the total effect over eight hours is similar."
Though the laboratory investigations did not provide any evidence in favour of either product the final questionnaire completed by the parents showed some patient preference for Nutrizym. There was some discrepancy (unexplained) between the information on stool frequency and character and the occurrence of abdominal pain obtained during the course of the trial, when there was no patient preference, and the information obtained at the end, when some of the parents modified their views in favour of Nutrizym. Clearly it is more convenient, especially for those patients who take a high dose of pancreatic preparation, to be able to reduce the number of tablets.

With the exception of the two children whose coefficients of fat absorption were nil (table III) values obtained for the children while on pancreatic replacement therapy were comparable with those in previous reports (Harris et al., 1955; Ross, 1955; Matthew and Spector, 1961), and the mean value $(70 \%)$ was some $28 \%$ less than normal $(96 \% \pm 4 \%$ ) (Matthews and Spector, 1961).

The apparent absence of fat absorption in cases 2 and 5 is difficult to explain. Both children were taking high doses of pancreatic therapy (mean numbers of Pancrex $\mathrm{V}$ forte and Nutrizym tablets per week were 133 and 63 respectively for case 2 , and 378 and 214 respectively for case 5 ). One patient (case 2 ), aged 6.6 years, was on the 75th centile for weight, and the other (case 5), aged 8.7 years, was on the 10 th centile.

Pancreatic enzyme preparations, even in high dosage, do not eliminate the steatorrhoea of cystic fibrosis and it seems expedient to investigate other mechanisms which may influence fat absorption in this disease.

We thank E. Merck Ltd. for financial help and Mr. M. Fletcher for technical work. M.C.G. is in receipt of a grant from the Cystic Fibrosis Research Trust.

\section{References}

Anderson, C. M., et al. (1952). Lancet, 1, 836.

Bosnes, R. W., and Taussky, H. H. (1945). Fournal of Biological Chemistry, 158,581 .

Coltini, E. P., Gallina, D. L., and Dominguez, J. M. (1973). Fournal of Nutrition, 103, 11

Fawcett, J. K., and Scott, J. E. (1960). Fournal of Clinical Pathology, 13, 156. Harris, R., Norman, A. P., and Payne, W. W. (1955). Archives of Disease in Childhood, 30, 424

Knill-Jones, R. P., et al. (1970). British Medical fournal, 4, 21.

Lapey, A., et al. (1974). Fournal of Pediatrics, 84, 328.

Matthews, L. W., and Spector, S. (1961). Pediatrics, 27, 351.

Ross, C. A. C. (1955). Archives of Disease in Childhood, 30, 316.

Van de Kamer, J. H., Huinink, H. ten Bokkel, and Weijers, H. A. (1949). fournal of Biological Chemistry, 177, 347.

\title{
Pain Threshold Analysis in Patients with Osteoarthrosis of Hip*
}

\author{
SUSAN L. O'DRISCOLL, MALCOLM I. V. JAYSON
}

British Medical fournal, 1974, 3, 714-715

\section{Summary}

The pain threshold was measured in patients with osteoarthrosis of the hip. The pain threshold was significantly

*From a paper read at the Heberden Society Meeting, Bristol, June, 1974.

Department of Medicine, University of Bristol, Bristol BS2 8HW, and Royal National Hospital for Rheumatic Diseases, Bath

SUSAN L. O'DRISCOLL, M.B., M.R.C.P., Senior Registrar in Rheumatology MALCOLM I. V. JAYSON, M.D., M.R.C.P., Consultant Senior Lecturer in Rheumatology lower in patients who required surgery than in controls. After successful surgery the threshold rose to normal levels. In patients with few or no symptoms from their osteoarthritic hips the pain threshold was high. Insensitivity to pain does not predispose towards osteoarthrosis of the hip. Indeed, the severity of symptoms can be directly related to an increased sensitivity to pain in osteoarthritic subjects.

\section{Introduction}

Pain is generally regarded as a protective sensation. If the threshold for a noxious stimulus to just produce the symptom 